\title{
Twenty Years at Family Medicine!
}

Joshua Freeman, MD

(Fam Med. 2022;54(1):5-6.)

doi: 10.22454/FamMed.2022.496495

\begin{abstract}
"We entered medicine by learning that professionals should place the highest priority on patient needs, and now find ourselves in health systems operated as businesses that prioritize efficiency and profit."
\end{abstract}

A mazingly, at least to me, I have been with Family Medicine for over 20 years! In early 2001, I started soliciting and receiving submissions for a new feature section called "Innovations in Family Medicine Education," a venue to publish some of the new and creative curricula presented at the STFM Annual Spring Conference. Its first article was published later that year. "Innovations" submissions (unlike those of most of the other feature sections) were peer-reviewed with attention to rigorous evaluation methods, and when John Saultz became editor in chief 12 years ago, he asked me to stay on as one of the journal's assistant editors.

Since then, I have read, sent for review, and recommended for or against publication of many hundreds of articles. The journal is better every year. The articles published are better written, answer more important questions, and are more rigorously evaluated. Good evaluation is key in educational research because it helps to assure readers that what is described actually worked, and that it has a reasonable chance of working in their own settings if the same conditions apply. We've moved from sharing creative ideas to expecting evidence that these new ideas work; the move from sharing to proving is a big change. In addition, most of our survey research is now done through the Council of Academic Family Medicine (CAFM) Educational Research Alliance (first reported in a special article in Family Medicine in $2011^{2}$ ), and is of higher quality.
A recent positive change has been the outpouring of submissions related to the important topics of diversity, equity, and inclusion. ${ }^{3}$ These are major issues in our society, and it is heartening to see the serious and self-critical way that our discipline has been involved. One example is the special issue of Family Medicine devoted to curricula addressing racism, published in January 2019. As some of these papers documented, we still have a long way to go before medicine has enough diversity to look more like our patients and the overall population. But we should be proud that this issue, led by our 2018 editorial fellow, Dr BichMay Nguyen, was published before similar efforts in other medical journals.

Change, within both medicine and family medicine, has not always occurred in the direction I would have hoped. Residency training has become more flexible, with different programs having the opportunity to emphasize different areas. Family physicians are no longer assumed to be practicing in small towns, and as I spent my career as an urban, innercity doctor, I am glad that these practices are now considered legitimate family medicine. Indeed, it is now archetypal rural communities that suffer from not having enough doctors. And it is not as if our cities are now wellserved. Greater diversity in medicine would also help address this issue, but there has been insufficient change in the composition of medical students. We have made great progress in some areas; women are the majority of many medical school classes, and we have made significant strides in racial, ethnic, socioeconomic, and geographic diversity, but not nearly enough. 
As our clinical practices have changed, so have our relationships with our patients. People are now less likely to have continuity with a family physician. They see different physicians (or other clinicians) and are less likely to get to know any of them well. Most family physicians do not deliver babies or care for people in hospitals, and many see fewer children and do minor surgery less frequently. In general, family physicians see less variety in the patients we care for and the settings in which we work, which may make practice less interesting and less challenging. When in the hospital, people are cared for by hospitalists, who may be expert in the technical issues of care but know little about the patient they are caring for. Because they have had no prior relationship, they don't know how the person's disease and treatment interacts with their other conditions, and with their overall life. Of course, while having different doctors working in the outpatient area from those who work in the hospital, or nursing home, or doing home care, may not provide continuity, it is efficient-if efficiency means producing more widgets per doctor per hour. It makes more money for the employer.

While having different doctors play different roles such as hospitalists and ambulists may allow family physicians to achieve work-life balance through limited and predictable hours with little or no emergency call, this practice also fits with the concentration of physicians in large, multispecialty groups controlled by hospital-based corporations. The upside of fewer hours for physicians also has a downside, which includes the loss of the autonomy of the self-employed physician and, more importantly, a distancing of relationships between physicians and patients that can affect the cost of care, its quality, and the satisfaction of both physicians and patients.
But despite these changes, being a family physician remains incredibly satisfying. Our relationships with people are at the heart of our specialty. More than knowing the right answer, we must use accurate information to help patients to figure out what is right for them. We may struggle with the number of clicks in our EHR, we may legitimately be irritated when the emphasis in our health system seems to be more on making money for our employers than caring for our patients, but we can still take tremendous satisfaction from our day-to-day work. If our health nonsystem is incredibly costly and often seems to be focused on the bottom line rather than the health of the American people, we can still make a difference in people's health, and gain satisfaction for ourselves.

I try to maintain optimism and hope that, like the quality of research published in the journal Family Medicine, the quality of care delivered to the American people will improve. I believe that the skill and caring of family physicians will play an important role in making that happen.

Maybe I will still be around in 20 years to see how this develops.

CORRESPONDENCE: Address correspondence to Dr Joshua Freeman, jfreeman@kumc.edu.

\section{References}

1. Saultz J. Burnout. Fam Med. 2020;52(1):5-7. doi:10.22454/ FamMed.2020.598170

2. Mainous AG III, Seehusen D, Shokar N. CAFM Educational Research Alliance (CERA) 2011 Residency Director survey: background, methods, and respondent characteristics. Fam Med. 2012;44(10):691-693.

3. Freeman J. Something old, something new: the syndemic of racism and COVID-19 and its implications for medical education. Fam Med. 2020;52(9):623-625. doi:10.22454/ FamMed.2020.140670

4. Family Medicine. 2019;51(1). Accessed December 6, 2021. https://journals.stfm.org/familymedicine/2019/january/ 